\title{
Correlation of Total Sperm Count with Presence of Round Cells and Abnormal Sperm Morphology in Semen Analysis
}

\author{
Thejasvi Krishnamurthy and Yashica Gowda R*
}

Department of Pathology, Kempegowda Institute of Medical Sciences, Karnataka, India

\begin{abstract}
Background: Among the routine semen parameters,presence of round cells and morphological defects in sperms are important qualitative parameters in semen analysis. Detailing the "round cells" and qualitative defects in sperms becomes important as these factors affect fertility.In this study, we aim to categorise and assess the percentage of round cells and morphological defects of sperms in correlation with total sperm count.
\end{abstract}

Methods: 70 random semen samples were included which were collected from males being evaluated for infertility. They were divided into two groups based on the total sperm count. Papanicolaou stained smears were studied for categorisation of round cellsandqualitative defects in sperms. These were then correlated with total sperm count.

Result: We observed that both the groups showed presence of round cells and morphological defects in sperms with a slightly higher percentage in reduced sperm counts. Round cells observed in our study included immature germ cells, leucocytes and epithelial cells. Frequent morphological defects were round head, large head and coiled tail.

Conclusion: Round cells and morphologically defect sperms are frequently observed in semen samples with reduced sperm counts compared to normal sperm counts.

Keywords: Morphological Defects; Round Cells; Semen Analysis; Total Sperm Counts

\section{Introduction}

The prevalence of infertility is increasing in the recent years, current data suggests that male factor contributes to15$50 \%$ of the total cases. Male infertility is predominantly due to deficiencies in the semen. So, the basic means in evaluating male fertility is semen analysis which is a non-invasive screening method. It forms the vital part in diagnosing male infertility. ${ }^{[1,2,3]}$

Semen analysis involves both quantitative and qualitative parameters, of which sperm morphology is an important qualitative parameter which reflects the sperm production. It also predicts the sperm fertilising ability. Abnormal morphology of sperms is associated with reduction in fertilisation rates. ${ }^{[3]}$

Apart from sperm morphology, review of literature and WHO manual quotes the importance of detecting the presence of "round cells" in semen analysis and the need to differentiate them into spermatogenic and nonspermatogenic cells. ${ }^{[4]}$

The studies regarding qualitative defects like detection of morphologically abnormal sperms and the significance of "round cells" in semen samples have garnered lot of importance after the advent of in-vitro methods of fertilization when compared to studies of sperm count and motility.
The current study was done to explore the association of sperm morphology and presence of round cells in reduced sperm counts in correlation with normal sperm counts.

\section{Materials \& Methods}

A descriptive study was done over a period of one year from June 2017 to June 2018. Among the subjects attending the laboratory for semen analysis, a total of 70 random samples were included in the study.

Inclusion criteria-samples from subjects within 45 years of age

Exclusion criteria-samples from subjects with age more than 45 years, samples which did not liquefy even after 1 hour, samples with loss of semen during collection

Semen sample were collected by masturbation into a sterile wide-mouthed plastic container, in the laboratory after a minimum of 3 days of abstinence. The samples were assessed after liquefaction for volume, colour, sperm concentration, sperm motility and total sperm count. Subjects were then divided into two groups based on the sperm concentration (according to WHO lower reference limit 15 million $/ \mathrm{ml}$ )

Group 1 - Samples with reduced sperm count $(<15$ million /ml) 
Group 2 - Samples with normal semen analysis $(\geq 15$ million /ml)

Group 1 samples were further subcategorised into-

\begin{tabular}{|c|c|}
\hline Category 1 & $0-5$ million/ml \\
\hline Category 2 & $6-10$ million/ml \\
\hline Category 3 & $11-14$ million/ml \\
\hline
\end{tabular}

The relation between sperm morphology and presence of round cells in each category of group 1 were assessed and compared with that of group 2 .

Sperm morphology was assessed from the smears prepared using a drop of semen and by routine feathering technique, fixed in isopropyl alcohol and stained by Papanicolaou method. Minimum of 200 spermatozoa were examined per sample (according to standards of 2010 WHO manual) under oil immersion(100x). The total \% of sperms with normal morphology and abnormal morphology were assessed and the type of abnormal forms were recorded.

We also assessed the percentage of background cells (round cells) and subcategorised them into immature sperm cells, epithelial cells and leucocytes.

\section{Results}

Routine semen parameters were assessed in 70 samples included in the study. Samples were divided into 2 groups, those with reduced sperm counts $(<15$ million $/ \mathrm{ml})$ and group 2 with normal semen analysis. Abnormal sperms were noted in 19/35 cases (54.2\%) of group 1 and 15/35 cases (42.8\%) in group 2(Fig 1-3). Presence of round cells were noted in 20/35 cases in group $1(57 \%)$ and 10/35 $(28 \%)$ in group 2 as shown in table 1 .

Group 1 with reduced sperm count was categorised further depending on the sperm concentration. Abnormal forms and round cells were assessed in each category. Category 1 showed majority of the abnormal sperm forms followed by category 2 . While the presence of round cells were more common in the category 2 followed by category 1 . (Table 2 )

The differentials of round cells (leucocytes, immature cells and epithelial cells) were assessed separately in group 1 and group 2. It was noted that round cells primarily seen were immature cells, $75 \%$ in group $1(15 / 20)$ and $80 \%$ $(8 / 10)$ in group 2. (Fig 4-5).Epithelial cells and leucocytes (Fig.5) were seen in both groups (Table 3 ).

Table 1: Number of semen samples with abnormal morphologies and round cells.

\begin{tabular}{|c|c|c|c|}
\hline & $\begin{array}{c}\text { No. of cases } \\
\text { With abnormal sperm morphology }\end{array}$ & \% & No. of case with round cells \\
\hline $\begin{array}{c}\text { Group 1 } \\
\text { (reduced sperm counts) }\end{array}$ & $19 / 35$ & 54.2 & $20 / 35$ \\
\hline $\begin{array}{c}\text { Group 2 } \\
\text { (normal sperm counts) }\end{array}$ & $15 / 35$ & 42.8 & $10 / 35$ \\
\hline
\end{tabular}

Table 2: Subcategorisation of cases with reduced sperm counts.

\begin{tabular}{|c|c|c|c|}
\hline & $\begin{array}{c}\text { No of cases with Abnormal } \\
\text { morphology }\end{array}$ & $\begin{array}{c}\text { No of cases with Round } \\
\text { cells }\end{array}$ \\
\hline $\begin{array}{c}\text { Category 1 } \\
(0-5 \text { million /ml })\end{array}$ & $10 / 14$ & 71 & $9 / 14$ \\
\hline $\begin{array}{c}\text { Category 2 } \\
(6-10 \text { million } / \mathrm{ml})\end{array}$ & $4 / 6$ & 66.6 & $4 / 6$ \\
\hline $\begin{array}{c}\text { Category 3 } \\
(11-14 \text { million } / \mathrm{ml})\end{array}$ & $5 / 15$ & 33.3 & $7 / 15$ \\
\hline
\end{tabular}

Table 3: Differential counts of round cells in each group.

\begin{tabular}{|c|c|c|c|c|c|c|}
\hline & Leucocytes & $\%$ & Immature sperm cells & $\%$ & $\begin{array}{c}\text { Epithelial } \\
\text { Cells }\end{array}$ & $10 / 20$ \\
\hline Group 1 & $8 / 20^{*}$ & 40 & $15 / 20$ & 75 & 30 \\
\hline Group 2 & $4 / 10^{* *}$ & 40 & $8 / 10$ & 80 & $3 / 10$ & 30 \\
\hline
\end{tabular}

*Group 1- 20 cases had round cells (denominator)

**Group 2 - 10 cases had round cells 


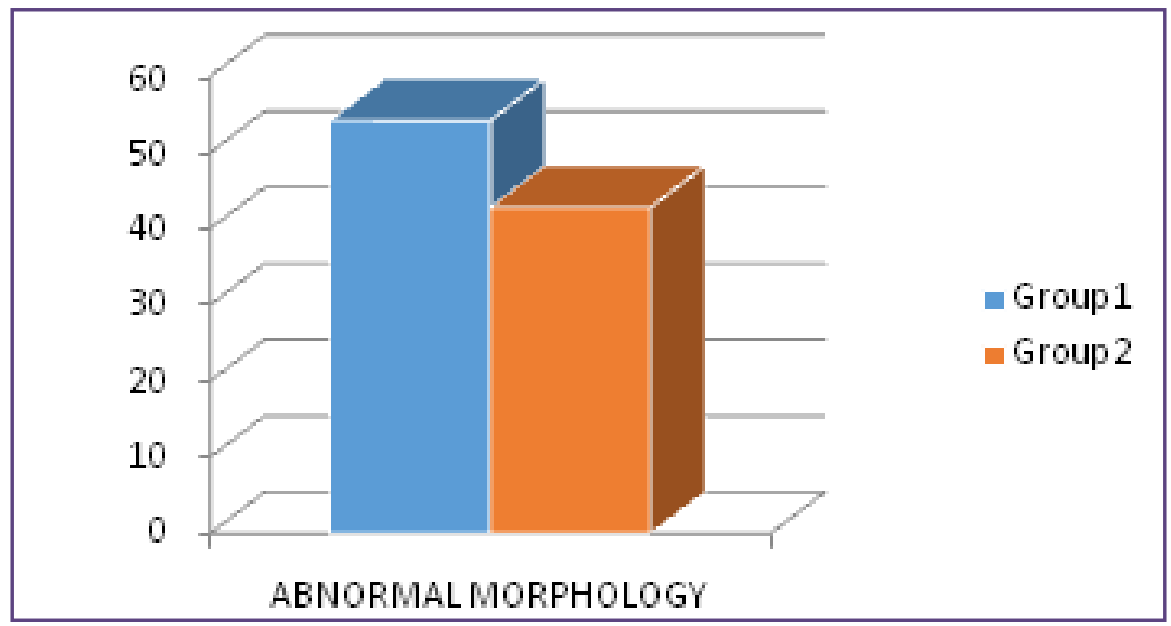

Graph 1. Distribution of abnormal sperms in Group 1 and Group 2.

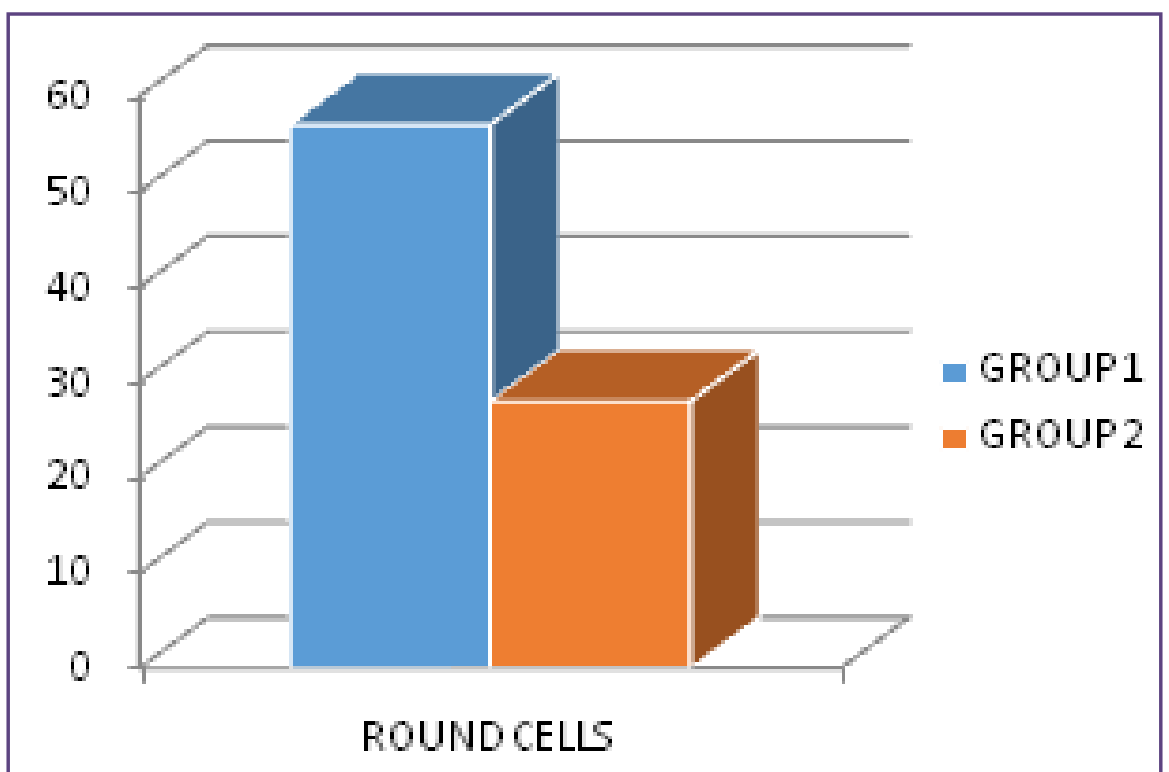

Graph 2.Distribution of round cells in Group 1 and Group 2

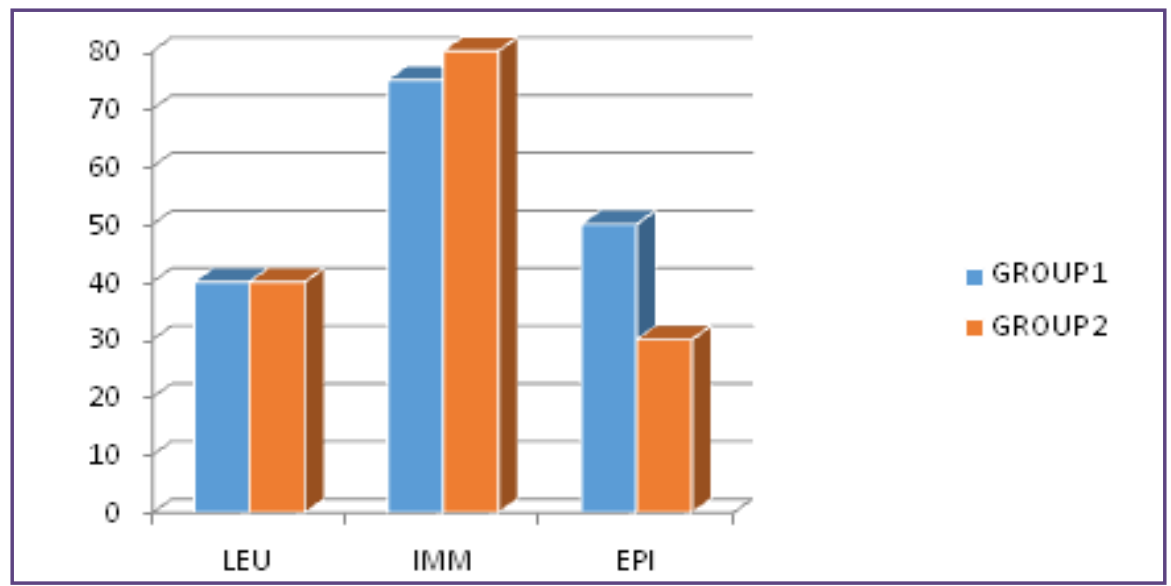

Graph 3.Distribution of differentials of round cells in Group 1 and group 2.(LEU-Leucocytes; IMM-Immature sperm cells; EPI-Epithelial cells 


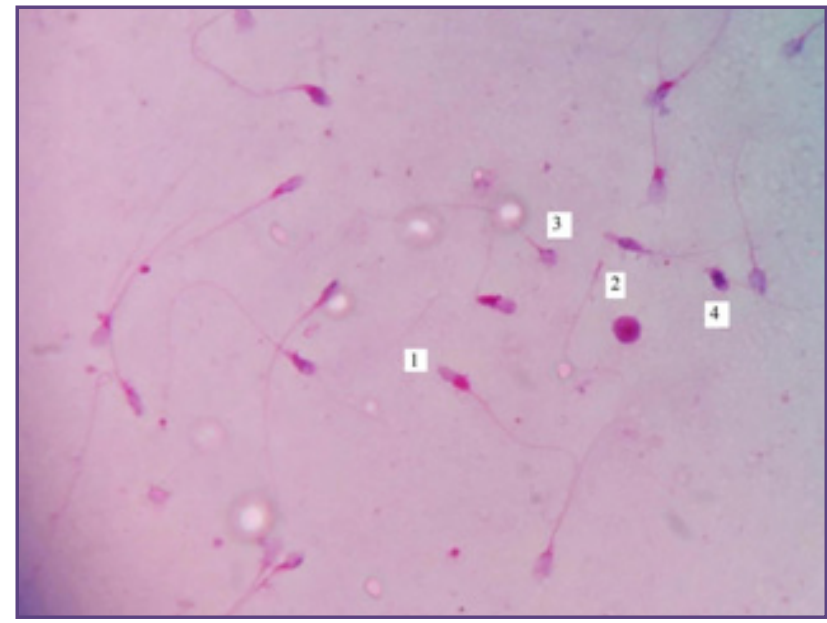

Fig. 1; Morphologic defects in sperm.1-thick middle piece 2-pin head,3-globose head,4-bent neck.

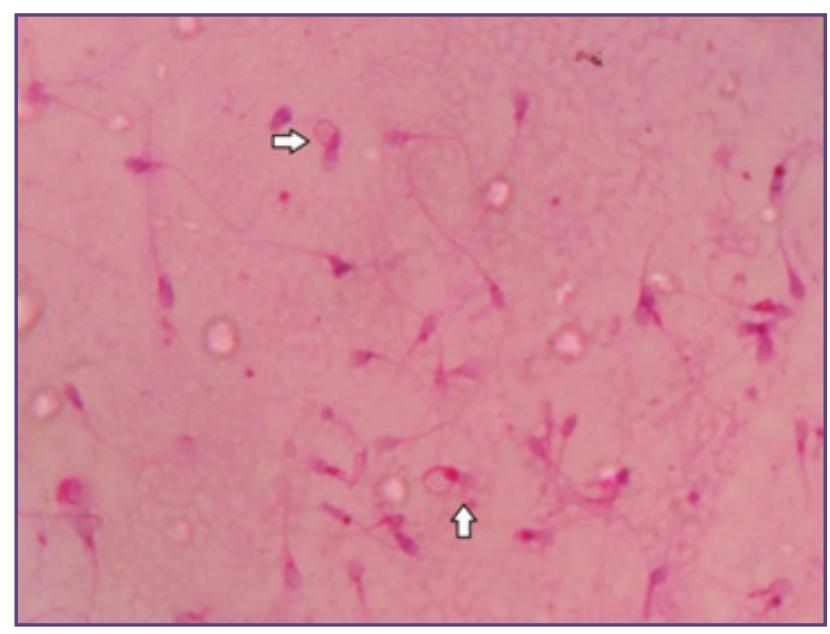

Fig. 3: Morphologic defects in sperm.Coiled tail.

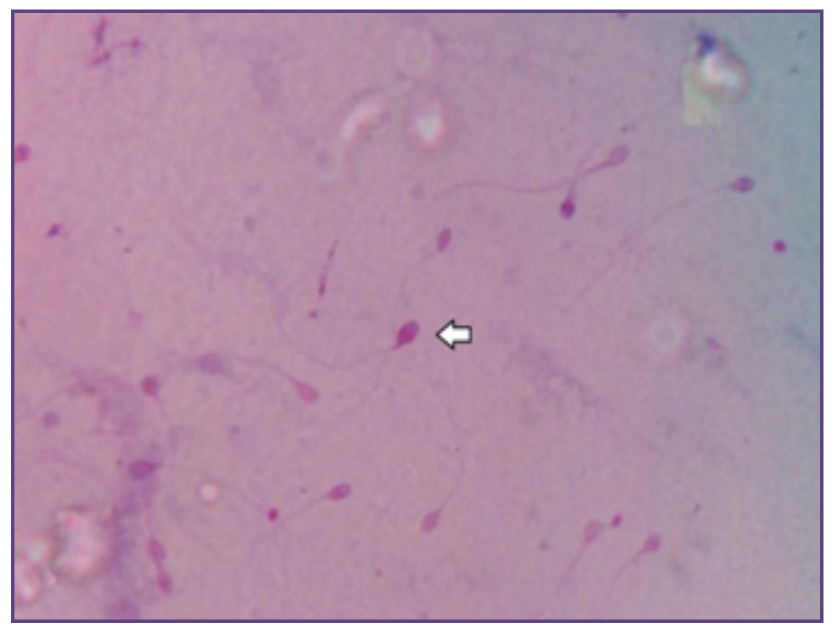

Fig. 2; Morphologic defects in sperm.Large head.

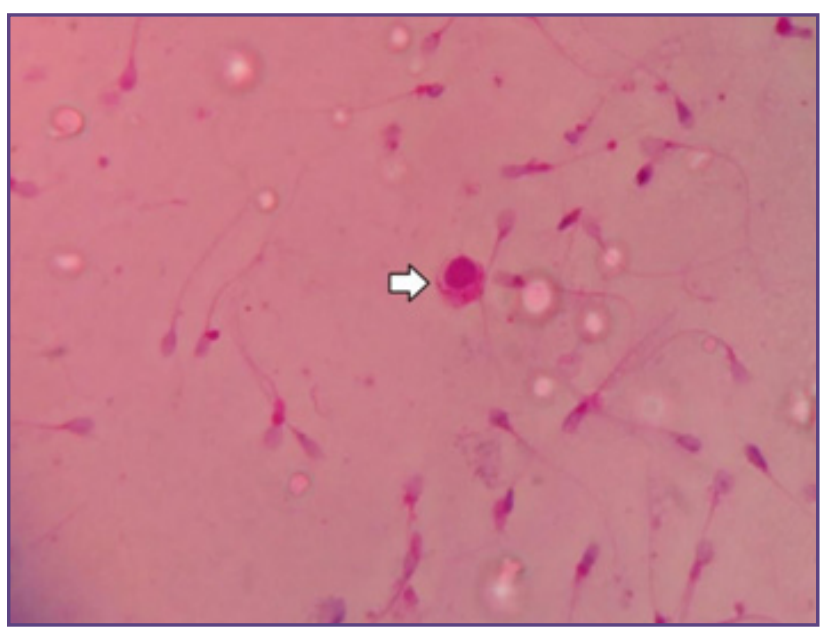

Fig. 4: Round cell.Spermatid.

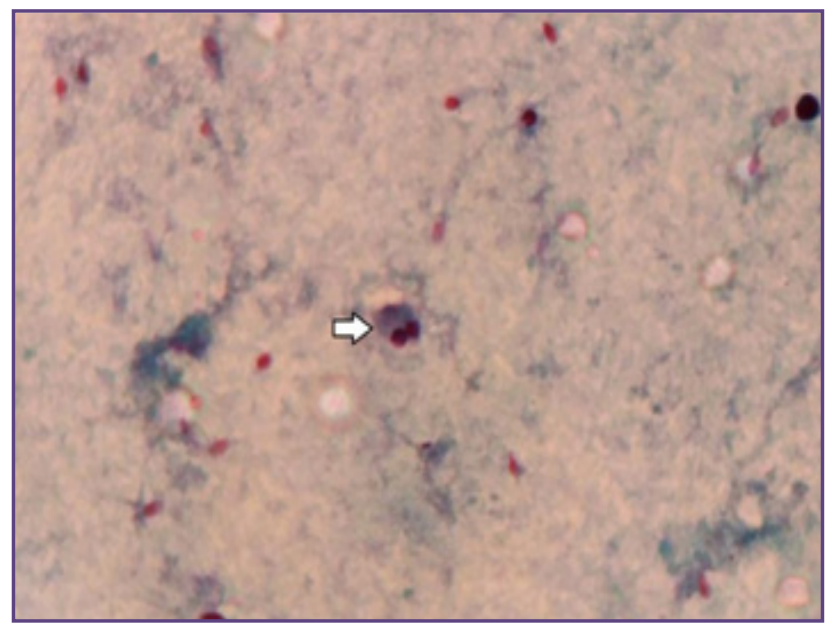

Fig. 5: Round cell.Neutrophil. 


\section{Statistical Analysis}

Comparison of abnormal morphology between the two groups shows that abnormal morphology is higher in group 2 which is statistically significant with a $p$ value of $<0.001$ by $\mathrm{X}^{2}$ test (Chi square test) (Graph 1)

However, there was a negative correlation between the type of morphological defect and total sperm count and $\mathrm{X}^{2}$ test showed there was no statistical significance with a $p$ value of 0.151 .

The round cells were counted as percentage of the total count in both the groups and was seen that their percentage were more in the group with reduced sperm counts. Statistical analysis of correlation showed that it was statistically significant with a $p$ value of 0.001 by $\mathrm{X}^{2}$ test. Hence there was positive correlation between round cells and total counts with $\mathrm{t}$ value of $-4.701(\mathrm{t}$ value $=$ test statistic) (Graph 2)

Among the differential counts of round cells, correlation of presence of leucocytes in both groups showed a negative correlation between the leucocytes and sperm count and was statistically not significant with a $p$ value of 0.232 by $\mathrm{X}^{2}$ test.

The same was observed with correlation of immature cells in both groups, there was no statistical significance with $\mathrm{p}$ value of 0.164 by $\mathrm{X}^{2}$ test.

\section{Discussion}

Sperm morphology is one of the important parameters in semen analysis. Normal sperm contains head with smooth oval configuration and well-defined acrosome, middle piece and tail. ${ }^{[3,4]}$ Morphological defects can be found in different parts of the sperm and these defects can be reversible or irreversible. ${ }^{[2]}$

Various studies have described with direct relation of sperm counts and abnormal morphology. They have reported that the defects increase with decreasing sperm counts $^{[1]}$. The same was observed in our study. The percentage of abnormal forms in oligospermia was greater than in subjects with normal sperm counts. Among the subjects with low sperm counts, the number of abnormal sperms increased with decreased count i.e $71 \%$ of the cases showed abnormal sperms in the count less than 5 million/ $\mathrm{ml}$, while in the sperm count of 11-14 million / $\mathrm{ml}$ only 33 $\%$ the cases showed abnormal morphology of the sperms. Statistical analysis showed statistical significance by Chi square test $\left(\mathrm{X}^{2}\right)$ with a $\mathrm{p}$ value of $<\mathbf{0 . 0 0 1}$.

Defects in the head are the most common ${ }^{[2,5]}$ as observed in our study. Various defects we observed were large head/ globose head. The next common findings were double head, pin head, microhead. Abnormalities of the tail were observed in fewer cases. And most of these cases had more than one defect.

Only few studies have compared abnormal morphology in reduced and normal sperm counts. ${ }^{[2,6,7]}$ Moreover, the presence of morphological abnormalities have been associated with spontaneous abortion. ${ }^{[2,8,9]}$

Round cells in semen refers to spermatogenic cells like immature sperm cells and non spermatogenic cells like leucocytes and epithelial cells. ${ }^{[10,11]}$ In our study, $57 \%$ of the subjects in group 1 had round cells and $28 \%$ in group 2 . It was also observed that the percentage of round cells were more common in moderate and severe oligospermia than in patients with mild oligospermia. $\mathbf{X}^{2}$ test showed statistical significance with a $p$ value of 0.001

The differential counts of round cells showed $75 \%$ were immature sperms in group 1 and $80 \%$ in group 2. Our results were comparable to the study by Patil PS et al, ${ }^{[1]}$ Fedder et al ${ }^{[12]}$ Gandini et al ${ }^{[13]}$ and Ariagno et al . ${ }^{[14]}$

The presence of immature cells provides us information about the abnormalities in spermatogenesis and its association with infertility.

Correlation of the presence of leucocytes in both the groups showed equal incidence in both reduced and normal sperm count. Hence, indicating a negative correlation between leucocytes and sperm count and was statistically not significant with a $p$ value of 0.232 . This was also observed in a study by Patil PS et al ${ }^{[1]}$ and Politich et al. ${ }^{[15]}$ Also ,the presence of pus cells indicates inflammatory condition of the male genital tract. ${ }^{[1,10]}$ Abnormal morphology and presence of round cells could be a cause for male subfertility which requires further evaluation and appropriate treatment after follow up. ${ }^{[1]}$

In the current study, correlation of abnormal morphology and presence of immature sperms between reduced and normal sperm counts proved that there is an increase in the presence of abnormal sperms and immature sperms with decreasing total counts.

\section{Conclusion}

Round cells and morphologically defect sperms are frequently observed in semen samples with reduced sperm counts compared to normal sperm counts.

Correlation of round cells and morphological defects in sperms with total sperm count acts as a screening test for further evaluation in male infertility. Moreover, differentiation of round cells and categorisation of qualitative defects in sperms is of merit in assessing fertility and plays an indispensable role in In-vitro fertilisation. 


\section{Reference}

1. Patil PS, Humbarwadi RS, Patil AD, Gune AR. Immature germ cells in semen-correlation with total sperm count and sperm motility. J cytol .2013;30:185-9

2. Goyal R, Kotru M, Gogia A, Sharma S. Qualitative defects with normal sperm counts in a patient attending infertility clinic. Indian J Pathol Microbiol .2018;61:233-5

3. Ara MJ, Hussain SMB, Rashid MU. Role of male partners in 100 infertile couples. JAFMC Bangladesh.2015 June;11(1):50-3

4. World Health Organisation. WHO Laboratory Manual for the examination and processing of human semen,5th ed. Geneva: WHO Press 2010.

5. Nikolettas N, Kupker W, Demirel C, Schopper B, Blasig C, Sturm R. Fertilisation potential of spermatozoa with abnormal morphology. Human Reprod 1999;14(1):47-70

6. Karabulut A, Tekin A. Alterations in the morphology and motility of spermatozoa: Relation with sperm count. Pam Med J 2013;6:1-4.

7. Andrade R. Sperm parameters in men with suspected infertility. Sperm characteristics, strict criteria sperm morphology analysis and hypoosmotic swelling test. J Reprod Med 2001;46:577-82

8. Cao X, Cui Y, Zhang X. Lou J, Zhou J, Wei R et al. The correlation of sperm morphology with unexplained recurrent spontaneous abortion: A systematic review and meta analysis. Oncotarget 2017;8:55646-56

9. Auger J, Eustache F, Andersen AG, Irvine DS, Jorgensen N, Skakkebaek NE et al. Sperm morphological defects related to environment, lifestyle and medical history of 1001 male partners of pregnant women from European cities. Hum Reprod 2001;16:2710-7

10. Johanisson E, Campana A, Luthi R, de Agostini A. Evaluation of roundcells in semen analysis: A comparative study. Human reproduction Update.2000;6(4):404-412

11. Palermo DG, Neri QV, Cozzubbo T, Cheung S, Pereira N, Rosenwaks Z. Shedding light on the Nature of Seminal round cells. PLoS OBE .2016 March;11(3):1-18

12. Fedder J, Askjaer SA, Hjort T. Non spermatozoal cells in semen: Relationship to other semen parameters and fertility status of the couple. Arch Androl 1993;31:95-103.

13. Gandini L, Lenzi A, Lombardo F, Pacifi R, Dondero F. Immature germ cell separation using a modified discontinuous percoll gradient technique in human semen. Human Reprod 1999; 14:1022-7

14. Ariagno J, Curi S, Mendeluk G, Grinspon D, Repetto H, Chenio $\mathrm{P}$ et al, Shedding of immature germ cells. Arch Androl 2002;48:127-31

15. Politich JA, Wolff H, Hill JA, Anderson DJ. Comparison of methods to enumerate white blood cells in semen. Fertil Steril 1993:60 :372-5.

*Corresponding author:

Dr. Yashica Gowda R, No.52, 11th cross,1st main, Telecom layout, Jakkur Post, Bengaluru-560 064 Karnataka, India

Phone: +917829501915

Email: ygowda31@gmail.com

Financial or other Competing Interests: None. 